\title{
Atık Çelik Lif Takviyeli Pomza İçeren Reaktif Pudra Betonun Rijit Kaplama İmalatında Kullanımı
}

\author{
Abdulrezzak BAKIȘ* \\ Bitlis Eren Üniversitesi, Mühendislik Mimarlık Fak. İnşaat Mühendisliği Bölümü, Bitlis
}

\begin{abstract}
$\ddot{O} \mathbf{z}$
Günümüzde beton yol kaplamaları, çoğunlukla $\mathrm{C} 30 / 37$ betonu gibi normal dayanımlı betonlarla inşa edilmektedir. $\mathrm{Bu}$ çalışmada, rijit kaplama inşasında $\mathrm{C} 30 / 37$ betonu yerine, atık çelik lif takviyeli pomza içeren reaktif pudra betonun (P-RPB) kullanılabilirliği araştırılmıştır. Çalışmada, C30/37 betonu, kontrol karışımı olarak seçilmiştir. $\mathrm{Bu}$ çalışmada yeni bir beton olan P-RPB betonu üretilmiştir. Çalışmada $\mathrm{C} 30 / 37$ betona, 28 gün $20^{\circ} \mathrm{C}$ standart su kürü uygulanmıştır. P-RPB' ye ise, 28 gün $20^{\circ} \mathrm{C}$ standart su kürü ve kombine kür olmak üzere 2 farklı kür uygulanmıştır. Çalışma sonucunda; standart su kürü sonrası, C30/37 beton basınç dayanımı 41,8 MPa, eğilme dayanımı 5,0 MPa bulunmuştur. P-RPB'nin 28 gün $20^{\circ} \mathrm{C}$ standart su kürü sonrası basınç dayanımı 71,2 MPa, eğilme dayanımı 8,2 MPa bulunmuştur. Kombine kür sonrası P-RPB'nin basınç dayanımı 105,2MPa, eğilme dayanımı 12,5 MPa bulunmuştur. Çalışma sonuçları, P-RPB betonun rijit üstyapı inşasında beton kaplama olarak kullanılabilirliğini göstermiştir.
\end{abstract}

Anahtar kelimeler: Rijit Üstyapı, Pomza, Reaktif Pudra Beton, Kombine Kür, Atık Lifli Beton.

\section{Usability of Waste Steel Fiber-Reinforced Reactive Powder Concrete Containing Pumice in Rigid Pavement Construction}

\begin{abstract}
Today concrete pavements are mostly constructed by normal resistant concretes such as C30/37. In this study the usability of waste steel fiber-reinforced reactive powder concrete containing pumice (P-RPC) instead of C30/37 in rigid pavement construction, was researched. In the study $\mathrm{C} 30 / 37$ concrete was chosen as control mixture. $\mathrm{P}$ RPC concrete was produced in this study as a new concrete. In the study, $20^{\circ} \mathrm{C}$ standard water cure was applied to $\mathrm{C} 30 / 37$ concrete for 28 days. Whereas, two different cures as $20^{\circ} \mathrm{C}$ standard water cure for 28 days and combined cure were applied to P-RPC. As a result of study after standard water cure C30/37 concrete compressive strength was found as $41.8 \mathrm{MPa}$ and flexural strength was found as 5.0 $\mathrm{MPa}$. After 28 days $20^{\circ} \mathrm{C}$ standard water cure of P$\mathrm{RPC}$ was found as 71.2 $\mathrm{MPa}$ and flexural strength was found as 8.2 $\mathrm{MPa}$. After combined cure compression strength of P-RPC was found as 105.2 MPa and flexural strength was found as 12.5 MPa. The study results showed the usability of P-RPC as concrete pavement in rigid superstructure construction.
\end{abstract}

Keywords: Rigid Superstructure, Pumice, Reactive Powder Concrete, Combined Cure, Waste Steel Fiber.

\section{Giriş}

Karayolu üstyapıları rijit ve esnek üst yapılar olmak üzere iki grupta ele alınmaktadır [1]. Rijit üstyap1, sıkıştırılmış zemin üzerine alttemel tabakası yapılarak, bu alttemelin üzerine beton dökülerek oluşturulur. İlk beton yollar ABD'de yapılmıştır [2]. Trafiğe açılan bir karayolunda tek şeritten gün boyunca geçen ticari araç miktarının 5000'in üzerinde olması durumunda, karayolu üstyapısının rijit olması koşulunu şart koymaktadır [3]. Sürekli artış eğilimi gösteren ağır ticari araç sayıları dikkate alınarak yakın bir zamanda rijit üstyapı inşaatlarına geçileceği düşünülmektedir [4]. Ülkemizde beton kaplamalı yollar deneme amaçlı Afyon ilinde yapılmış ve olumlu sonuçlar alınmıştır. Ayrıca terminallerde, otopark alanlarında, şehir içi yol ve benzeri yerlerde beton kaplamaların yapımı hız

\footnotetext{
"Sorumlu yazar:abakis@beu.edu.tr

Geliş Tarihi: 13/04/2018 Kabul Tarihi: 13/06/2018
} 
kazanmıştır. Beton yollar, asfalt kaplama yollara göre bakım giderleri düşük ve daha uzun hizmet ömrü nedeniyle ekonomik çözümler sunabilir. Esnek üstyapı yapımında, bitümün 1sıtılma evresinde çevre kirliliği oluşabilmektedir. Ayrıca bitümün zaman içerisinde oksitlenmeden dolayı, asfaltta yaşlanma denilen olumsuz bir değişim meydana gelmektedir. Bundan dolayı, esnek üstyapılarda kullanılan asfalt kaplamalar sürekli bakım ve onarım gerektirirler. Rijit üstyapı beton yol kaplamasında asfalt yaşlanması gibi bir problem yoktur. Bu sebepten dolayı rijit üstyapı beton yol kaplamalarının, esnek üstyapı asfalt kaplamalarına kıyasla daha iyi bir performans gösterdiği söylenebilir. Ülkemizde beton yolların geliştirilmesiyle, ithal edilen ve ülke ekonomisine ciddi zarar veren asfalt kaplama bağlayıcısı olan bitümün kullanımı azalmış olacaktır. Bu şekilde, asfalt temininde dışa bağımlılık azalacak, çimento gibi yerli malzemelerden üretilen yeni tip beton yol kaplamaları üretilecektir. Bunun sonucunda yol yapımında asfalt malzemesinin kullanılmamasından dolayı, ülke ekonomisine önemli bir katk1 sağlanmış olacaktır. Beton kaplamalı rijit üstyapıların planlama aşamasındaki asıl amaç, rijit üstyapı kalınlık ve inşa aşamasında kullanılacak malzeme karakteristiklerinin belirlenmesidir [5]. Çimento içerikli malzemeler ile yüksek mekanik performans kazanılması amacıyla, beton üzerine birçok çalışma yapılmıştır. Bu çalışmaların sonucunda, yüksek performanslı betonlar ortaya çıkmıştır $[6,7,8,9]$. Bu tip betonlardan birisi de reaktif pudra betondur (RPB). RPB'lar yüksek basınç ve eğilme dayanımına sahiptir. RPB karışımı içerisinde çimento, silis dumanı, kuvars kumu, kuvars tozu, çelik lif, su ve süper akışkanlaştırıcı bulunmaktadır. RPB'nin basınç ve eğilme dayanımları 1sıl işlemli kürlerle artırılabilmektedir. Bu çalışmada kuvars agregası yerine pomza agregası kullanılmıştır. Çalışmada, RPB'da kullanılan çelik lifler yerine atık çelik lifler kullanılmıştır. Oluşturulan yeni tip betona, Atık çelik lif takviyeli pomza agregalı Reaktif pudra beton (P-RPB) ismi verilmiştir.

P-RPB betonda su/bağlayıcı miktarı 0,15 olarak alınmıştır. Betonda su/bağlayıcı oranının azaltılması, betonun stabilitesini artırmaktadır $[4,7,10,11,12]$.

Pomza, volkanik hareketler sonucu şekillenen ağırlık olarak hafif, gözenekli magmatik bir kayaç türüdür [13].Ülkemizde yüksek rezervde pomza yataklarının olduğu bilinmektedir. Dünya genelinde tespit edilen pomza kaynakları yaklaşık $18 \times 10^{9} \mathrm{~m}^{3}$ 'dür. Pomza kaynaklarının bulunduğu ülkelerin başında ABD, Türkiye ve İtalya gelmektedir [14]. Pomza agregası, beton üretim sektöründe sinırlı olarak yalıtım amaçlı kullanılmakta, ancak agreganın basınç dayanımı çok düşük olduğundan yapının taşıyıcı kısımlarında yapı betonu olarak kullanılamamaktadır. P-RPB betonu pomzadan üretilmiş olup, kalıba kendiliğinden yerleşme özelliğine sahiptir. P-RPB beton üretiminde, basınç ve eğilme dayanımını etkileyen faktörlerden birisi isıl işlemli kürlerdir.

Reaktif pudra betonuna uygulanan 1 sıl işlemin amacı, betonun içyapısında değişiklikler oluşturarak daha yüksek dayanım değerlerinin kısa sürede elde etmesini sağlamaktır. Betona uygulanan 1s1l işlemli kürlerden birisi kombine kürdür. Kombine kür, oluşturulan bir beton numunesine birkaç farklı kürün ara verilmeden ardı sıra uygulanmasıdır. Yüksek dayanımlı betonların aşırı gevrek davranış gösterdiği ve aniden kırılabildiği bilinmektedir. P-RPB beton üretiminde, betonun ani gevrek kırılmasını önlemek amacıyla, oluşturulan beton karışımı içerisine sanayi atığı çelik teller katılmıştır.

P-RPB karışımında Portland çimentosu, ince pomza agregası, pomza tozu, silis dumanı, atık çelik lifler, süper akışkanlaştırıcı ve su bulunmaktadır. P-RPB betonunda su/bağlayıcı oranı düşük tutularak, betonun basınç ve eğilme dayanımı artırılmıştır. Bu çalışmada, P-RPB beton üretiminde CEM I 42,5 R türü çimento kullanılmıştır. Beton agregası olarak karışımda pomza kullanılmıştır. Pomza agregası kuvars agregasına kıyasla daha ucuz bir malzemedir. İri pomza agregasının içerisinde, beton dayanımını olumsuz yönde etkileyen, birbirinden bağımsız birçok gözenek mevcuttur. $\mathrm{Bu}$ gözeneklerden dolayı taşıyıcı beton üretiminde kullanımı sınırlı kalmıştır. Bu çalışmada pomza agregası öğ̈̈tüldügünden, içerisindeki gözenek miktarı oldukça azaltılmıştır. Bu durum beton dayanımını olumlu yönde etkilemiştir. Lifli beton üretiminde, çelik lifler beton üretim maliyetini artırmaktadır. Sanayi atığı çelik tellerin beton üretiminde kullanılmasıyla beton üretim maliyeti düşürülebilir. Bu çalışmada, yol kaplama betonuna alternatif olarak, P-RPB'nin kullanılabilirliği araştırılmıştır. Çalışmada; geleneksel beton kaplamayı ifade eden C30/37 normal dayanımlı betonu, kontrol karışımı olarak seçilmiştir. $\mathrm{Bu}$ çalışmada, beton yol kaplama inşası için, P-RPB beton üretiminde, sanayi atığı çelik lifler kullanılarak, farklı bir çalışma yapılmıştır. Atık çelik lifler Bitlis Mesleki ve Teknik Anadolu Lisesi'nin makine atölyesinden temin edilmiştir. Çalışmada hazırlanan P-RPB karışımı içerisine, atölyedeki CNC torna tezgâhlarındaki çalışma sonrası ortaya çıkan atık çelik lifler katılmıştır. 


\section{Malzeme ve Yöntem}

\subsection{Malzeme}

Çalışma aşamasında üretilen bütün betonlarda, bağlayıcı olarak TS EN 197-1 standardına uygun CEM I 42,5 R türü çimento kullanılmıştır. Çimentonun, kimyasal, fiziksel ve mekanik özellikleri Tablo 1'de verilmiştir [15].

Tablo 1. Çimentonun kimyasal, fiziksel ve mekanik özellikleri

\begin{tabular}{lc}
\hline Özellikler & Değer \\
\hline $\mathrm{SiO}_{2}(\%)$ & 18,70 \\
$\mathrm{Al}_{2} \mathrm{O}_{3}(\%)$ & 5,35 \\
$\mathrm{Fe}_{2} \mathrm{O}_{3}(\%)$ & 3,26 \\
$\mathrm{CaO}(\%)$ & 63,69 \\
$\mathrm{MgO}(\%)$ & 1,53 \\
$\mathrm{SO}_{3}(\%)$ & 2,69 \\
$\mathrm{~K}_{2} \mathrm{O}(\%)$ & 0,75 \\
$\mathrm{Na}_{2} \mathrm{O}(\%)$ & 0,44 \\
$\mathrm{Cl}(\%)$ & 0,02 \\
$\mathrm{~K}$ ızdırma Kaybı (\%) & 3,57 \\
Özgül Ağırlık (g/cm $\left.{ }^{3}\right)$ & 3,19 \\
Özgül Yüzey (cm²/g) & 3770 \\
Priz Başı (dakika) & 167 \\
Priz Sonu (dakika) & 213 \\
Basınç Dayanımı 2 Gün (MPa) & 26,33 \\
Basınç Dayanımı 28 Gün (MPa) & 56,49 \\
\hline
\end{tabular}

P-RPB beton üretiminde kum agregası olarak 0,15-0,6 $\mathrm{mm}$ dane çaplı pomza kumu kullanılmıştır. Üretimde, pomza agrega tanelerinin arasını doldurarak düşük boşluk oluşturmak amacıyla, P-RPB beton karışımında, pomzanın öğütülmesiyle elde edilen 0-0,045 mm dane çaplı pomza tozu kullanılmıştır. Pomza kumu ve pudrasının görünümü Şekil 1' de gösterilmektedir.

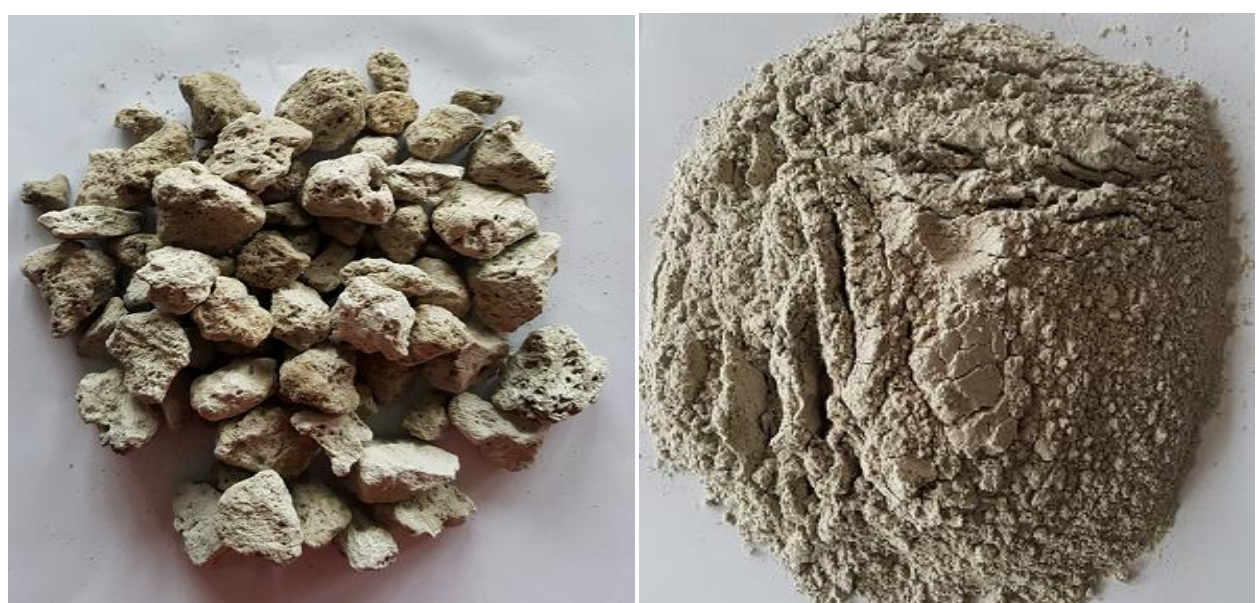

Şekil 1.P-RPB beton üretiminde kullanılan pomzanın pudra haline getirilmiş görünümü

Çalışmada kullanılan pomza agregasının kimyasal ve fiziksel özellikleri Tablo 2'de görülmektedir [16, 17].

Tablo 2. Pomza agregası kimyasal ve fiziksel özellikleri

\begin{tabular}{lc}
\hline Özellikler & Değer \\
\hline $\mathrm{SiO}_{2}(\%)$ & 71
\end{tabular}




\begin{tabular}{lc}
$\mathrm{Al}_{2} \mathrm{O}_{3}(\%)$ & 13 \\
$\mathrm{Fe}_{2} \mathrm{O}_{3}(\%)$ & 2,6 \\
$\mathrm{CaO}(\%)$ & 0,8 \\
$\mathrm{MgO}(\%)$ & 0,7 \\
$\mathrm{SO}_{3}(\%)$ & 0,61 \\
$\mathrm{~K}_{2} \mathrm{O}+\mathrm{Na}_{2} \mathrm{O}(\%)$ & 9,11 \\
$\mathrm{~K} 1 \mathrm{zd}$ 1rma Kaybı (\%) & 2,18 \\
Özgül Ağırlık(g/cm $\left.{ }^{3}\right)$ & 2,07 \\
Sertlik (MOHS) & 5,43 \\
Porozite (\%) & 43 \\
Su Emme (\%) & 29 \\
\hline
\end{tabular}

Çalışmada kullanılan sanayi atığı çelik teller, yaklaşık 0 ila1 $\mathrm{mm}$ çapında ve 0 ila10 mm uzunluktadır. Ortalama lif çapı $0,5 \mathrm{~mm}$ alınmıştır. Ortalama lif uzunluğu $5 \mathrm{~mm}$ alınmıştır. Atık lif takviyeli P-RPB üretiminde kullanılan sanayi atığı çelik lifler Şekil 2'de gösterilmektedir.

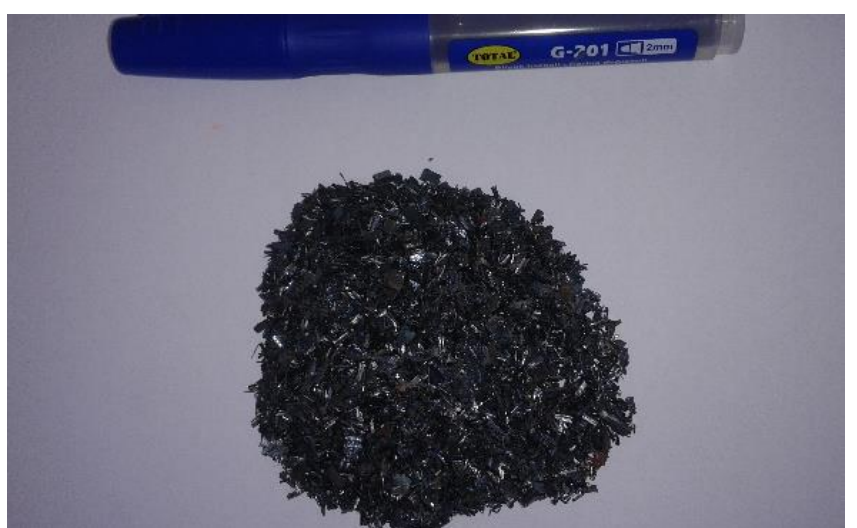

Şekil 2.P-RPB beton üretiminde kullanılan sanayi atığı çelik teller

Atık çelik liflerin fiziksel ve mekanik özellikleri Tablo 3’te gösterilmektedir.

Tablo3.Çelik lif fiziksel ve mekanik özellikleri

\begin{tabular}{lccccc}
\hline Lif Tipi & Çap (mm) & Boy $(\mathrm{mm})$ & Narinlik & Çekme Dayanımı (MPa) & Özgül Ağırlık $\left(\mathrm{g} / \mathrm{cm}^{3}\right)$ \\
\hline Çelik Lif & 0,50 & 5 & 10 & $>350$ & 7,40 \\
\hline
\end{tabular}

Kontrol numunesi (C30/37)beton üretimi için, karışımda kırmataş kireçtaş1 agregası ve beton karışım suyu olarak Bitlis şehir şebeke suyu kullanılmıştır.

\subsection{Yöntem}

Kontrol betonu üretiminde karışım ağırlıkları Tablo 4'te gösterilmiştir.

Tablo 4.Kontrol betonu(C30/37) karışım ağırlıkları

\begin{tabular}{lc}
\hline Malzeme & Ağırlık $\left(\mathrm{kg} / \mathrm{m}^{3}\right)$ \\
\hline Portland Çimentosu & 450 \\
$0-4 \mathrm{~mm}$ & 800 \\
$4-8 \mathrm{~mm}$ & 390 \\
$8-16 \mathrm{~mm}$ & 560 \\
$\mathrm{Su}$ & 200 \\
Toplam & 2400 \\
\hline
\end{tabular}

Tüm beton numuneleri, basınç deneyi için $150 \times 150 \times 150 \mathrm{~mm}$, eğilme deneyi için ise $100 \times 100 \times 400 \mathrm{~mm}$ boyutunda oluşturulmuştur. Beton numunelere, kalıptan alındıktan sonra 28 gün $20^{\circ} \mathrm{C}$ standart kür havuzundaki su içerisine alınmıștır. Kür havuzundan çıkarıldıktan sonra numunelere basınç-eğilme testleri yapılmıştır. P-RPB beton üretimlerinde, reaktif pudra beton karışım oranları 
dikkate alınmıştır. Reaktif pudra betonda, karışımdaki Portland çimentosu miktarı göz önüne alınarak, karışım içerisindeki çimento harici malzemeler ağırlıkça oranlandırılmaktadır.

Reaktif pudra beton karışım hesaplamasında ulusal veya ülke dışı herhangi bir standart bulunmamaktadır. Reaktif pudra beton üretimlerinde farklı karışım teorileri kullanılmışır. Karışım tasarımlarında, Mooney süspansiyon viskozite modeli oluşturulmuştur $[4,18,19]$. Mooney süspansiyon viskozite modeli dikkate alınarak meydana gelen karışım verilerinden, çoğunlukla kullanılan karışım oranları birimsel olarak Tablo 5'te gösterilmiştir [20,21].

Tablo 5.Reaktif pudra betonların karışım miktarları

\begin{tabular}{|c|c|c|c|c|c|c|}
\hline \multirow[b]{2}{*}{ Malzeme } & \multicolumn{4}{|c|}{ RPB200 } & \multicolumn{2}{|c|}{ RPB800 } \\
\hline & \multicolumn{2}{|c|}{ Lifsiz } & \multicolumn{2}{|c|}{ Lifli } & Silis Agrega & Çelik \\
\hline Çimento & 1 & 1 & 1 & 1 & 1 & 1 \\
\hline Silis Sumanı & 0,25 & 0,23 & 0,25 & 0,23 & 0,23 & 0,23 \\
\hline $\begin{array}{l}\text { Kuvars Kum } \\
(150-600 \mu \mathrm{m})\end{array}$ & 1,1 & 1,1 & 1,1 & 1,1 & 0,5 & - \\
\hline $\begin{array}{l}\text { Kuvars Pudras } 1 \\
\left(\mathrm{~d}_{50}=10 \mu \mathrm{m}\right)\end{array}$ & - & 0,39 & - & 0,39 & 0,39 & 0,39 \\
\hline Süper akışkanlaştırıcı & 0,016 & 0,019 & 0,016 & 0,019 & 0,019 & 0,019 \\
\hline Çelik Tel $(\mathrm{L}=12 \mathrm{~mm})$ & - & - & 0,175 & 0,175 & - & - \\
\hline Çelik Tel $(\mathrm{L}=3 \mathrm{~mm})$ & - & - & - & - & 0,63 & 0,63 \\
\hline $\begin{array}{l}\text { Çelik Agrega } \\
(<800 \mu \mathrm{m})\end{array}$ & - & - & - & - & - & 1,49 \\
\hline $\mathrm{Su}$ & 0,15 & 0,17 & 0,17 & 0,19 & 0,19 & 0,19 \\
\hline
\end{tabular}

Tablo 5'te verilen karışım oranları dikkate alınarak oluşturulan P-RPB beton numunelerin $\mathrm{su} /$ bağlayıcı miktarı 0,15 ve silis dumanı/çimento miktarı 0,23 olarak alınmıştır. Tablo 5 'te verilen RPB karışım oranları göz önüne alınarak, P-RPB üretiminde süper akışkanlaştırıcı miktarı, çimento miktarının 0,019 katı alınarak metreküp başına $15 \mathrm{~kg}$ olarak karışım içerisine katılmıştır. P-RPB betonu karışım miktarları Tablo 6'da görülmektedir.

Tablo 6.P-RPB betonu karışım ağırlıkları

\begin{tabular}{lc}
\hline Malzeme & Ağırlık $\left(\mathrm{kg} / \mathrm{m}^{3}\right)$ \\
\hline Portland Çimento & 773 \\
Silis Dumanı & 178 \\
Pomza Kumu $(0,15-0,6 \mathrm{~mm})$ & 850 \\
Pomza Tozu $(0-0,045 \mathrm{~mm})$ & 302 \\
Süper akışkanlaştırıcı & 15 \\
Endüstri atığı çelik tel & 135 \\
Su & 147 \\
Toplam & 2400 \\
\hline
\end{tabular}

Kombine kürler için, literatür araştırmalarında herhangi bir standardın olmadığı görülmüştür. Bakış vd (2015) yılı çalışmalarında, oluşturdukları betona 9 farklı tipte kombine kür uygulanmıştır. Çalışma sonucunda, maksimum basınç ve eğilme dayanımı veren kombine kür şeklinin, 7 gün $20^{\circ} \mathrm{C}$ standart su kürü, ardı sıra 2 gün $90^{\circ} \mathrm{C}$ sıcak su kürü ve son olarak ardı sıra 2 gün $180^{\circ} \mathrm{C}$ etüv kürü şeklinde uygulanan kombine kür olduğu belirtilmiştir [4, 8].P-RPB beton üretiminde priz süresince herhangi bir sıkıştırma basıncı uygulanmamıştır. Kalıptan çıkartılan numunelere, $20^{\circ} \mathrm{Cstandart} \mathrm{su} \mathrm{kürü} \mathrm{ve} \mathrm{kombine}$ kür şeklinde 2 farklı kür tipi uygulanmıştır. Kombine kürde, 7 gün $20^{\circ} \mathrm{C}$ standart su kürü, ardından 2 gün $90^{\circ} \mathrm{C}$ sıcak su kürü ve hemen ardından 2 gün $180^{\circ} \mathrm{C}$ etüv kürü şeklinde kombine kür uygulanmıştır. Kür sonrası tüm numunelere basınç-eğilme deneyleri yapılmıştır. Basınç deneyleri TS EN 12390-3: 2010, eğilme deneyleri TS EN 12390-5: 2010 standartları göz önüne alınarak yapılmıştır [22, 23].

\section{Bulgular ve Tartışma}

Tüm tip betonların basınç-eğilme deney sonuçları Tablo 7'deverilmiştir. 
Tablo 7.Basınç-eğilme deney sonuçları

\begin{tabular}{lcccc}
\hline \multirow{2}{*}{ Beton Tipi } & \multicolumn{2}{c}{ Basınç Dayanımı(MPa) } & \multicolumn{2}{c}{ Ĕgilme Dayanımı (MPa) } \\
\cline { 2 - 5 } & $20^{\circ} \mathrm{C}-28$ gün & Kombine & $20^{\circ} \mathrm{C}-28$ gün & Kombine \\
& Su Kürü & Kür & Su Kürü & Kür \\
\hline Kontrol Betonu (C30/37) & 41,8 & - & 5,0 & - \\
P-RPB Betonu & 71,2 & 105,2 & 8,2 & 12,5 \\
\hline
\end{tabular}

Tüm numunelerin basınç dayanımları Şekil 3'te grafiksel olarak gösterilmektedir.

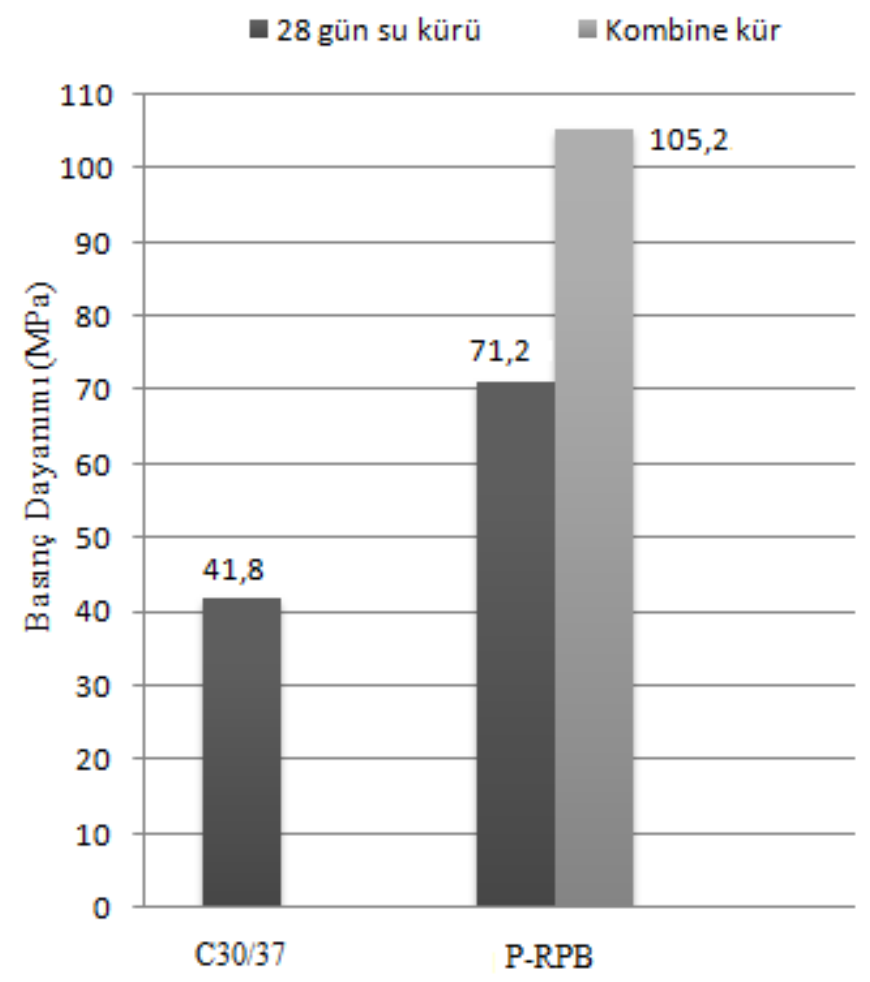

Şekil 3.Kür sonrası betonların basınç dayanımı

P-RPB beton basınç dayanımının kontrol betonu (C30/37) basınç dayanımından su kürü altında \%70,33, kombine kür altında \%151,67 yüksek olduğu görülmektedir (Şekil 3). Bu durum, P-RPB betonun rijit yol kaplama inşasında kullanılabilirliğini ifade etmektedir.

P-RPB beton eğilme dayanımının kontrol betonu (C30/37) eğilme dayanımından su kürü altında $\% 64$, kombine kür altında \%150 yüksek olduğu görülmektedir (Şekil 4). Kaplama betonu için; minimum basınç dayanımının $28 \mathrm{MPa}$, minimum eğilme dayanımının 4,5 MPa olması gerektiğinden [3], Tablo 7, Şekil 3 ve Şekil 4'te P-RPB betonun rijit yol kaplaması olarak uygun şartları sağladığı söylenebilir. 


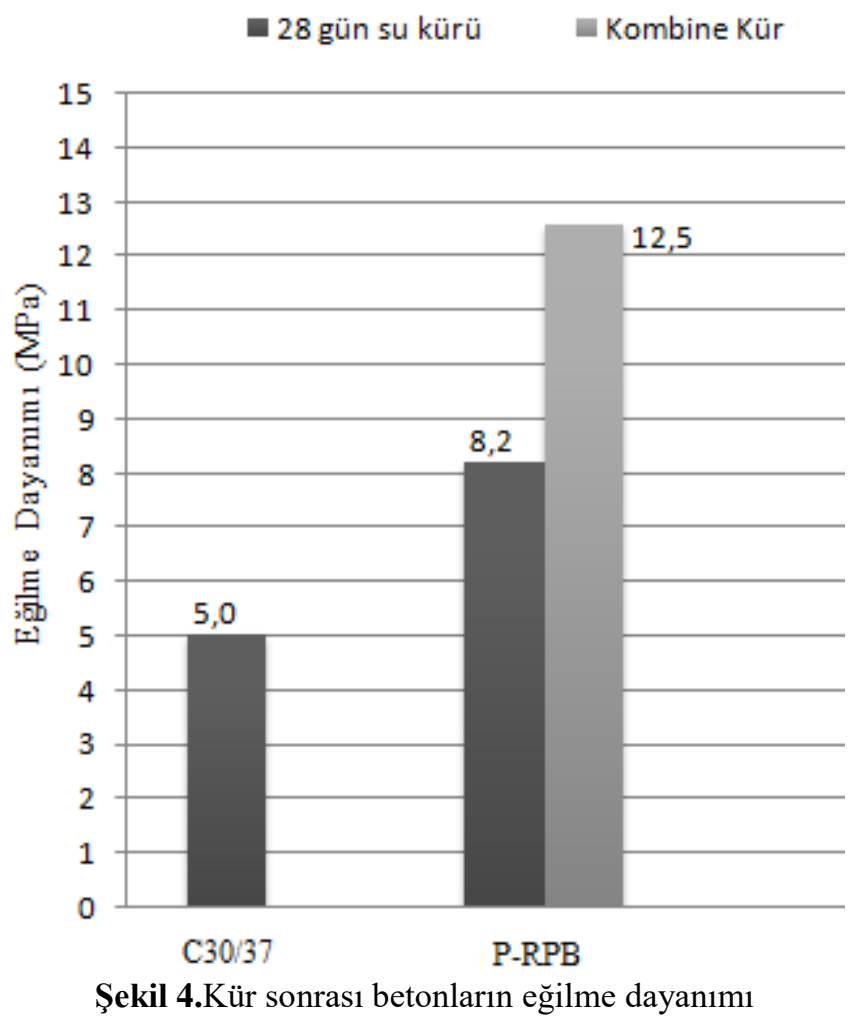

\section{Sonuç ve Öneriler}

Bu çalışmada, geleneksel yol kaplama betonuna alternatif olarak, sanayi atığı çelik lifli pomza içeren reaktif pudra betonun (P-RPB) kullanılabilirliği araştırılmışır. Pomza agregası aşırı gözenekli bir malzeme olduğundan basınç ve eğilme dayanımı düşüktür. Bu çalışmada pomza agregası, Reaktif pudra beton üretim yöntemine göre ögütülerek boşluk miktarı azaltılmıştır. Ülkemiz pomza rezervi bakımından zengin olmasına rağmen, içerisindeki yüksek miktarda gözeneklerden dolayı basınç ve eğilme dayanımı düşük olduğundan, inşaat sektöründe kullanım alanı sınırlıdır. Bu çalışma ile pomza içeren reaktif pudra beton üretimiyle, pomzanın inşaat sektöründe yaygın olarak kullanımı sağlanabilir. Beton karışımında lif kullanımının yapılarda stabilite, süneklik, beton dayanımı ve çatlak oluşumunu azaltmada katkı sağladığı bilinmektedir. Beton üretiminde lif olarak, polipropilen, cam, çelik ve diğer malzemeler kullanılabilmektedir. Beton üretiminde çelik lifler, yük altında oluşan enerjiyi sönümleme ve yüksek aderans nedeniyle, özellikle beton dayanımının artırılması ve çatlak oluşumunu azaltmada önemli katkı sağlamaktadır. Bu nedenle çalışmada P-RPB üretiminde atık çelik lif kullanılmıştır. Atık çelik liflerin, beton üretiminde lif maliyetini önemli ölçüde azaltabileceği göz ardı edilmemelidir.

Bakış vd (2015) yılı çalışmalarında, standart su kürü yanında, beton 9 farklı kombine kür tipi uygulanmıştır. Çalışma sonucunda, kombine kür sonrası beton basınç ve eğilme dayanımının standart su kürüne kıyasla daha yüksek olduğu belirtilmiştir [4, 8]. Bu çalışmada oluşturulan P-RPB numunelere standart su kürü yanında kombine kür de uygulanmıştır. Kombine kür sonrası beton basınç ve eğilme dayanımında artış görülmüştür.

Yüksek mukavemetli betonlar ile imal edilecek rijit kaplamaların asfalt kaplamalara kıyasla daha uzun ömürlü olduğu bilinmektedir. Her ne kadar rijit kaplamaların asfalt kaplamalara nazaran ilk yatırım maliyetinin yüksek olduğu fikri yaygın olsa da, uzun vadede rijit kaplamaların bakım/onarım maliyetlerinin daha düşük olduğu göz önünde tutularak daha ekonomik olabileceği söylenebilir. Daha önceki çalışmalarda, sanayi atığı liflerin P-RPB beton üretiminde kullanılmasıyla ilgili bir çalışmaya rastlanılmamıştır. Bu çalışmada, beton yol kaplaması için P-RPB beton oluşturularak, yeni bir çalışma yapılmıştır. Bu deneysel çalışmada aşağıdaki sonuçlar bulunmuştur:

P-RPB betonun su/bağlayıcı oranı 0,15 'dir. Kaplama betonu için mevzuatlarda maksimum su/bağlayıcı miktarının 0,40 ile 0,45 arası olması gerektiğinden [3], üretilen yeni P-RPB betonu rijit yol kaplaması olarak kullanılabilir. P-RPB betonun 28 gün $20^{\circ} \mathrm{C}$ standart su kürü sonrası basınç dayanımı 
71,2 $\mathrm{MPa}$, eğilme dayanımı 8,2 MPa olarak bulunmuştur. P-RPB betonun kombine kür sonrası basınç dayanımı 105,2 $\mathrm{MPa}$, eğilme dayanımı 12,5 MPa olarak elde edilmiştir. Kaplama betonu için mevzuatlarda minimum basınç mukavemetinin $28 \mathrm{MPa}$, minimum eğilme dayanımının 4,5 MPa olması gerektiğinden [3], P-RPB betonu rijit yol kaplaması olarak kullanılabilir. P-RPB'nin beton yol şartname değerlerini sağladığı Tablo 8' de görülmektedir.

Tablo 8.P-RPB ile şartname değerlerinin karşılaştırılması

\begin{tabular}{lccccc}
\hline \multirow{2}{*}{ Su/Bağlayıcı } & \multicolumn{2}{c}{ Basınç Dayanımı(MPa) } & \multicolumn{2}{c}{ Eğilme Dayanımı (MPa) } \\
\cline { 2 - 5 } & Su Kürü & Kombine & Su Kürü & $\begin{array}{c}\text { Kombine } \\
\text { Kür }\end{array}$ \\
\cline { 3 - 6 } & & 28 & 28 & 4,5 & 4,5 \\
Şartname Değeri & 0,45 & 71,2 & 105,2 & 8,2 & 12,5 \\
P-RPB Betonu & 0,15 & & & \\
\hline
\end{tabular}

\section{Teşekkür}

Çalışmalarımda destek çıkan başta Bitlis Eren Üniversitesi Rektörlüğü’ne, Teknik Bilimler Meslek Yüksekokulu müdürü Dr. Öğr. Üyesi Faruk ORAL'a ve Van Gölü Yapı Kalite Kontrol Ltd. Şti’ ye teşekkürlerimi sunarım.

\section{Kaynaklar}

1. Ağar E., Öztaş G., Sütaş İ. 1998. Beton Yollar, İstanbul Teknik Üniversitesi Yayınları, İstanbul.

2. Arslan M. 2007. Beton Yol Kaplamalarında Alternatif Beton ve Yapım Yöntemi Araştırmaları. Gazi Üniversitesi Bilimsel Araştırma Projesi, Ankara.

3. Tunç A. 2007. Yol Malzemeleri ve Uygulamaları, 2. Baskı, Nobel Yayın Dağıtım.

4. Bakış A. 2015. Rijit Yol Üstyapı İnşasında Reaktif Pudra Betonun (RPB) Kullanılabilirliğinin Araştırılması. Doktora Tezi, Atatürk Üniversitesi Fen Bilimleri Enstitüsü, Erzurum.

5. Bayrak O.Ü. 2007. Rijit Üstyapı Tasarımına Yeni Bir Yaklaşım. Doktora Tezi, Atatürk Üniversitesi Fen Bilimleri Enstitüsü, Erzurum.

6. Aitcin P. C. 2000. Cements of Yesterday and Today Concrete of Tomorrow. Cement and Concrete Research, 30: 1349-1359.

7. Taşdemir M.A., Bayramov F., Kocatürk N., Yerlikaya M. 2004. Betonun Performansa Göre Tasarımında Yeni Gelişmeler, Beton 2004 Kongresi Bildiriler, İstanbul.

8. Hattatoglu F., Bakis A. 2017. Usability of ignimbrite powder in reactive powder concrete road pavement. Road Materials and Pavement Design, 18(6): 1448-1459.

9. Türkmenoğlu Z.F., Kılıç A.M., Depci T. 2015. Van Yöresi Pomzası ile Üretilmiş Kendiliğinden Yerleşen Hafif Betonların Mekanik Özelliklerinin İncelenmesi. Çukurova Üniversitesi Mühendislik-Mimarlık Fakültesi Dergisi, 30: 105-116.

10. Roux N., Andrade C., Sanjuan M.A. 1996. Experimental Study of Durability of Reactive Powder Concretes. Journal of Materials in Civil Engineering, 8: 899-1561.

11. Yalçınkaya Ç., Yazıcı H. 2011. Agrega Hacminin Reaktif Pudra Betonunun Mekanik ve Büzülme Özelliklerine Etkileri, THBB Beton 2011 kongresi, İstanbul, 150-159.

12. Tam C.M., Vivian W.Y., Tam K.M. 2012. Assessing Drying Shrinkage and Water Permeability of Reactive Powder Concrete Produced in Hong Kong. Construction and Building Materials, 26 (1): 79-89.

13. Karaman M.E., Kibici Y. 2008. Temel Jeoloji Prensipleri, Belen Yayınc1lık ve Matbaacilık, Ankara. 
14. Dinçer İ., Orhan A., Çoban S. 2015. Fizibilite Raporu, Pomza Araştırma ve Uygulama Merkezi, Nevşehir.

15. Çimsa Çimento Sanayi ve Ticaret A.Ş. 2017. http://www.cimsa.com.tr (Erişim Tarihi: 03.04.2017)

16. TOKYAP İnşaat Limited Şti. 2017. http://wwww.pomza.net (Erişim Tarihi: 10.04.2017)

17. Efe T. 2011. Edremit Travertenleri ve Van Gölü Kuzeyinde Yüzeylenen Pomzaların Çimento Sektöründe Kullanılabilirliğinin Araştırılması. Yüzüncü Yıl Üniversitesi Fen Bilimleri Enstitüsü, Yüksek Lisans Tezi, 147s, Van.

18. İpek M. 2009. Reaktif Pudra Betonların Mekanik Davranışına Katılaşma Süresince Uygulanan Sıkıştırma Basıncının Etkileri. Doktora Tezi, Sakarya Üniversitesi Fen Bilimleri Enstitüsü, Sakarya.

19. Larrard F., Sedran T. 1994. Optimization of Ultra-High-Performance Concrete by the Use of a Packing Model. Cement and Concrete Research, 24 (6): 997-1009.

20. Richard P., Cheyrezy M. 1995. Composition of Reactive Powder Concretes. Cement and Concrete Research, 25: 1501-1511.

21. Bakış A., Işık E., El A.A., Ülker M. 2017. A Study on the Mixture Ratio of Pumice Powder Concrete on the Concrete Pavement and the Construction of Building. IOSRJournal of Mechanical and Civil Engineering (IOSR-JMCE), 14(3): 83-90.

22. TS EN 12390-3. 2010. Beton-Sertleşmiş Beton Deneyleri-Bölüm 3: Deney umunelerinin Basinç Dayanımınin Tayini, TSE, Ankara.

23. TS EN 12390-5. 2010. Beton - Sertleşmiş Beton Deneyleri - Bölüm 5: Deney Numunelerinin Eğilme Dayanımının Tayini, TSE, Ankara. 